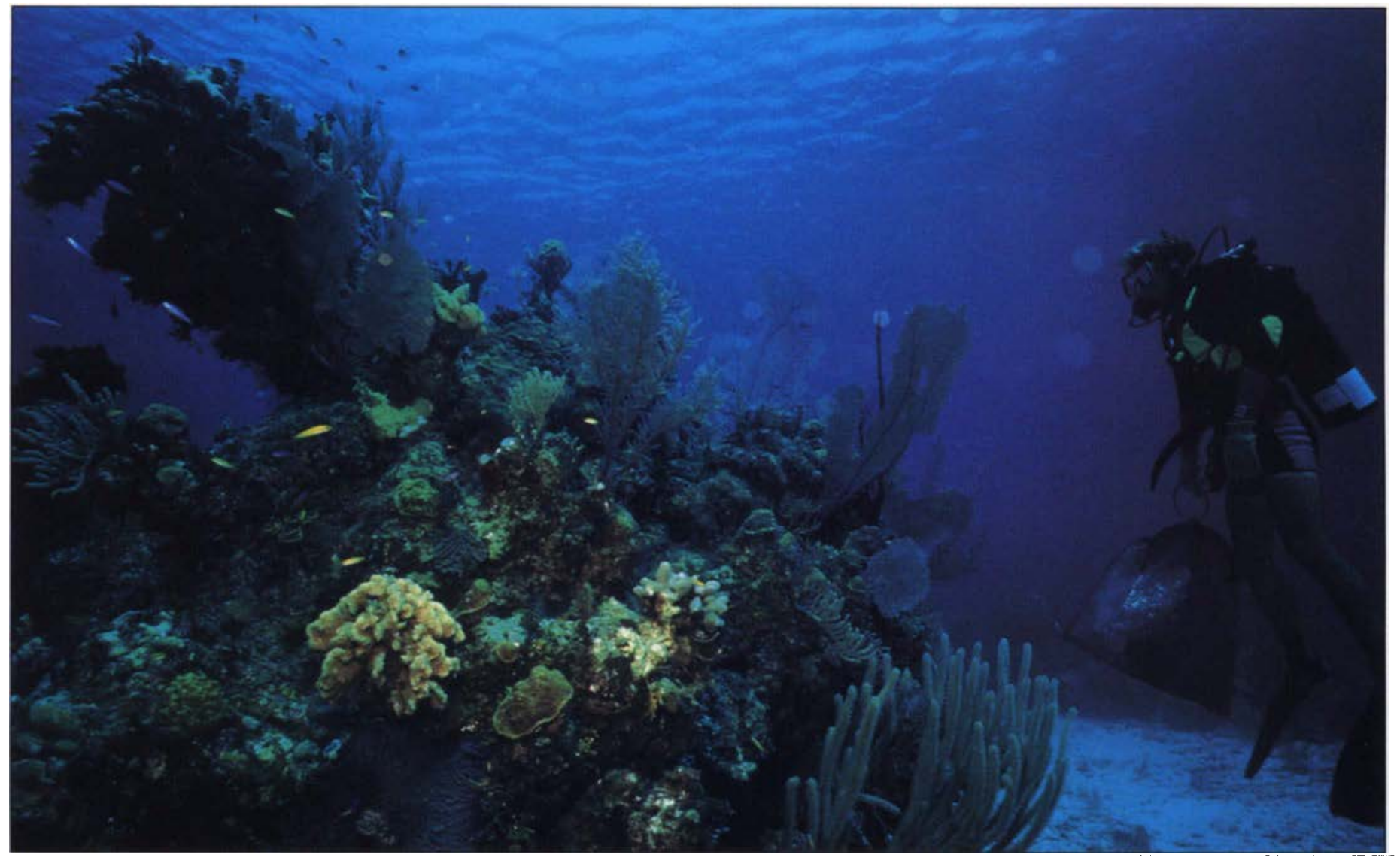

\title{
Sea Grant seeks new drugs from the sea
}

The enormous biodiversity in marine environments has been difficult to quantify because of limitations in marine taxonomy. The vast numbers of unique marine organisms provide an exciting source for new drugs.

William Fenical

\begin{abstract}
After more than 20 years of leadership in the field of marine drug discovery, Sea Grant researchers are now demonstrating that marine organisms are an excellent source of new drugs. New treatments have been discovered for arthritis and cancer, and novel molecular probes have been commercialized that allow studies of previously unknown cellular processes. Through patenting and licensing, UC has begun to receive significant royalties for these discoveries. As this field matures, it has become clear that the world's oceans contain an enormous wealth of medical information that will continue to contribute to the discovery of new cures for human disease.
\end{abstract}

$A$ lthough the modern pharmaceuAtical industry can design and synthesize many new drugs, it continues to rely on compounds from nature to provide new drug leads as well as chemical probes that can be used to better understand the complex metabolic processes involved in disease. Traditionally, drugs have been derived from nature - this is the legacy of herbal medicine. Thousands of years ago, early societies learned through trial and error that many plants contained substances with significant curative properties. Over the centuries, these "natural products" became used in more sophisticated ways, ultimately leading to the purification of single-component drugs. Some of the best known natural drugs are aspirin, originally discovered in the bark of the willow tree and used by indig- enous societies to treat tooth pain; morphine, a natural pain killer extracted from the opium poppy; and penicillin, the revolutionary antibiotic discovered in ordinary bread mold.

So far, natural drugs have been derived almost entirely from terrestrial sources. In recent decades, however, our search for new drug leads has become more compelling. Not only do drug-resistant strains of bacteria and viruses arise almost daily, but our search for new pharmaceutical leads in land-based plants and animals is proving less and less successful.

Thus it was inevitable that we would eventually turn to the sea. Not only does the ocean occupy nearly $80 \%$ of the Earth's surface, but in many marine organisms, particularly the "lower" life forms, we find exotic compounds arranged in completely 
different ways from those found in land plants and animals (also see page 47). And these different patterns of construction, or molecular structures, can lead to totally different mechanisms of action in the human body.

Only 20 years ago, we knew little about the inhabitants of the ocean and almost nothing about their abilities to reduce human suffering. With the establishment by Congress of the National Sea Grant College Program in 1966, this situation began to change dramatically.

Sea Grant's founders realized the enormous medical potential of marine plants and animals and incorporated into the program's charter a focus on developing marine medical resources. Sea Grant invested in this area of re-<smiles>CC1=C(CC/C(C)=C/CCC2=CCC(C3=CC(=O)O[C@@H]3O)O[C@@H]2O)C(C)(C)CCC1</smiles>

1. Manoalide

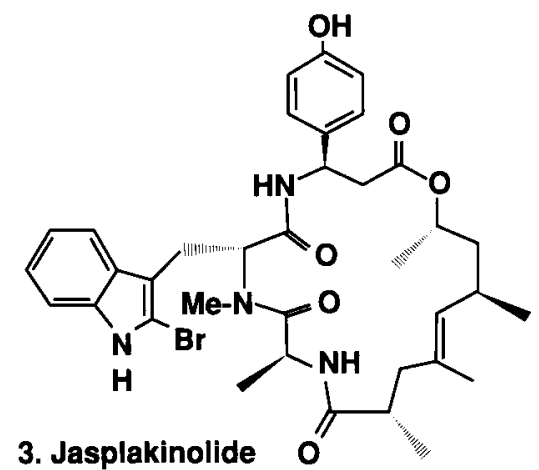<smiles>C[13CH3]</smiles>

5. Macrolactin A

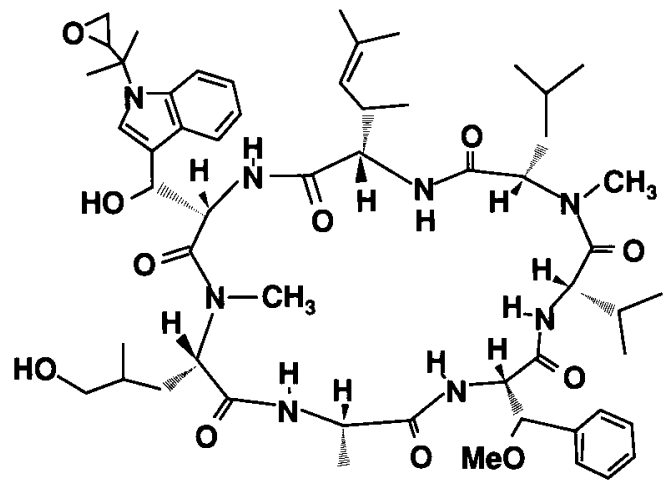

6. Cyclomarin A

search from the beginning, although it was often criticized for what then appeared to be an unscientifically founded "fishing expedition" for new compounds with medical potential. For many years, Sea Grant was the only federal agency investing in marine drug discovery, although today there are active marine pharmacology programs in several branches of the National Institutes of Health, including the National Cancer Institute and the National Institute for Allergy and Infectious Diseases.

As Sea Grant's involvement in marine natural products grew, the California program soon became the leader in this field of study. Programs developed at UC campuses throughout the state, notably at UC Santa

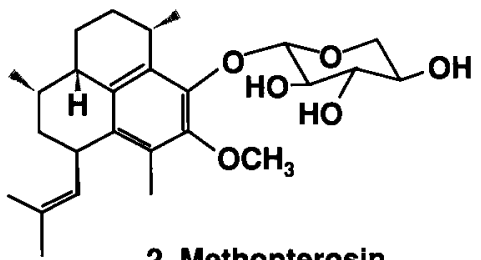

\section{Methopterosin}

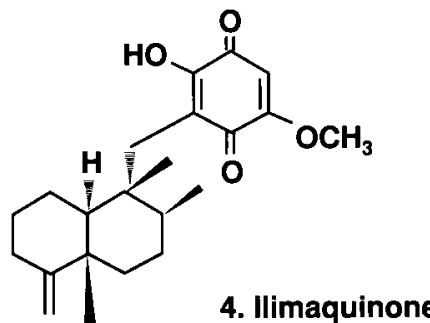

4. Ilimaquinone

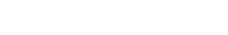

Fig. 1. Important Sea Grant drugs either marketed or in development as drugs or molecular probes.
Cruz, UC Santa Barbara and UC San Diego's Scripps Institution of Oceanography. By the early 1980s, California Sea Grant realized the even greater value of linking these programs to create an intercampus collaborative project called the Marine Chemistry and Pharmacology Program, which flourishes today.

California Sea Grant researchers have continued to lead the nation in their discoveries of new, medically important molecules. Their discoveries, based on the enormous diversity of marine organisms, have provided the foundation for the development of marine drugs both in academic laboratories and throughout the international pharmaceutical industry. Sea Grant discoveries have had an enormous impact on the directions of pharmaceutical research and led to our present belief that the oceans will be the frontier for drug discovery in the next century.

\section{Sea Grant discoveries}

Most of California Sea Grant's drug discovery research has focused on finding cures for the vast array of inflammatory diseases, particularly arthritis, and for cancer. Emphasis has been on investigating marine invertebrates that have evolved chemical defenses against predators. For example, soft-bodied sponges and soft corals have been especially productive sources of new drug candidates.

One of the first discoveries in California was the compound manoalide (fig. 1), a uniquely designed molecule extracted by Scripps scientists from the sponge Luffariella variabilis. Pharmacological studies at UC Santa Barbara showed manoalide to be a powerful anti-inflammatory agent, which has an entirely new way of acting in the body. The compound was patented by the University of California and licensed to Allergan Pharmaceuticals for development for treatment of psoriasis. Ultimately it was abandoned as a drug candidate because of its poor ability to penetrate the skin, but it has been developed as a commercial reagent for basic studies of an enzyme (phospholipase A2) that is indirectly continued on p. 48 
Tebo is focusing on a bacterium whose spores can bind a variety of metals. He hopes to exploit the magnetic properties of the bound metals to remove them from sediments, a process that could not only recover valuable metals for recycling but could also reduce the cost of sediment disposal by $90 \%$ or more. Tebo is presently working with a small California biotechnology firm to make this technology commercially feasible.

Some microorganisms seem capable of evolving abilities to deal with almost any toxic substance, and it is probable that marine microbes can be genetically engineered to be even more effective cleaner-uppers, a possibility that Tebo, among others, is exploring.

The application of biotechnology in the marine environment, in contrast to terrestrial systems, is only now being recognized as an important field for research, development and commercialization. But the development of new, commercially viable technologies for the assessment, monitoring, cleanup and prevention of pollution in coastal and estuarine waters is essential to sustained development of our coastal regions and watershed and requires a long-term commitment to science, education and outreach activities.

-Rosemary Amidei

The author is California Sea Grant's Assistant Director for External Relations.

\section{Further Reading}

Boyd TJ, Carlucci AF. 1993. Degradation rates of substituted phenols by natural populations of marine bacteria. Aquat Toxicol 25:71-82.

Ellwood DC, Hill MJ, Watson JHP. 1992. Pollution control using microorganisms and magnetic separation. In: Fry JC et al. (eds.). Microbial Control of Pollution. New York: Cambridge Univ $\operatorname{Pr}$ 48:59-88.

Pennisi E. 1996. Sorcerers of the sea: Making microbes do our dirty work. BioScience 46(4):236-9.

Tebo BM. 1995a. Metal precipitation by marine bacteria: Potential for biotechnological applications. In: Setlow, JK, (ed). Genetic Engineering - Principles and Methods. New York: Plenum 17:231-63.

Tebo BM. 1995b. Environmental Applications of Marine Biotechnology: Summary of a Workshop. La Jolla (CA): California Sea Grant College System. 32 p.

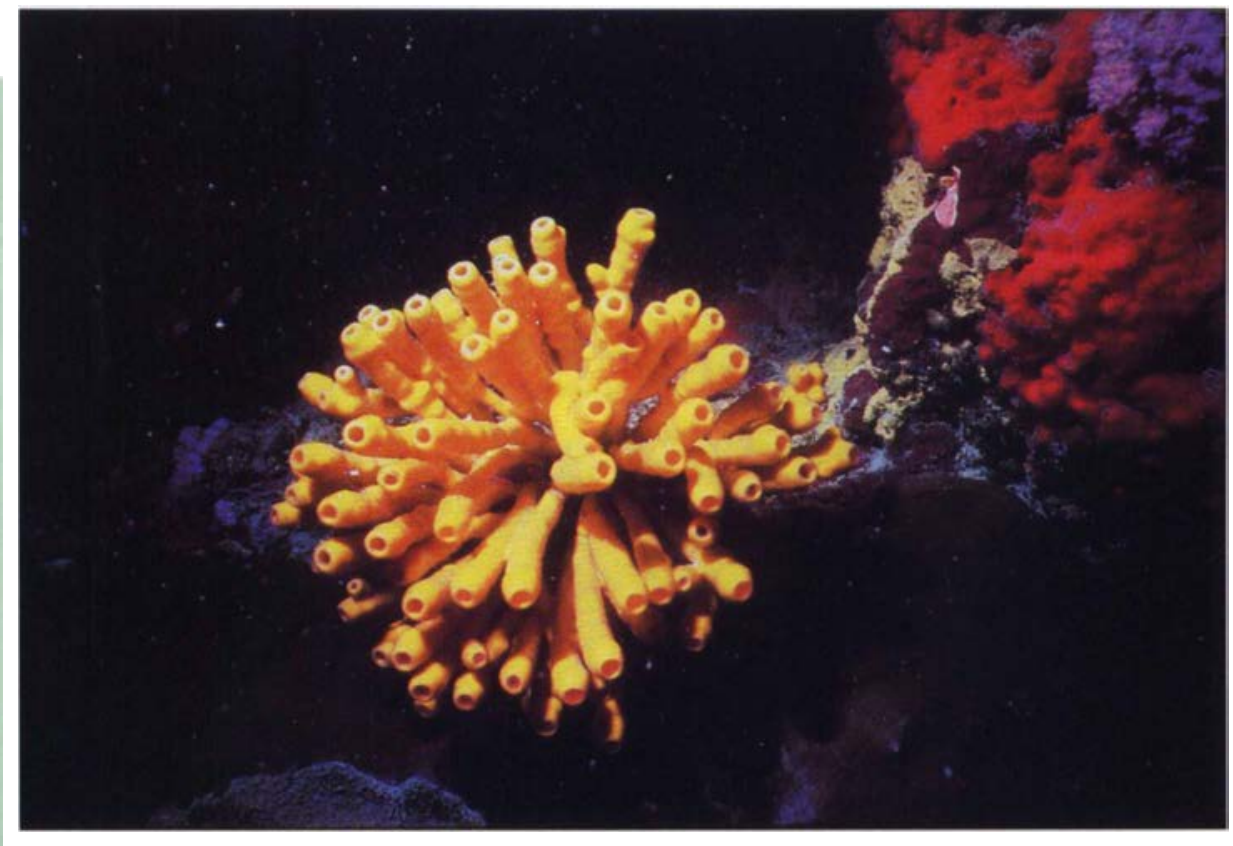

The marine sponge Auletta constricta contains jasplakinolide, a unique molecule currently under study at the National Cancer Institute for the treatment of cancer.

continued from p. 46

responsible for inflammation and pain. Manoalide continues to be widely used throughout the pharmaceutical industry as a molecular probe to provide new insight into the complex processes involved in inflammation. Thus it may well result, through synthetic drug design, in a new class of anti-inflammatory agents.

Perhaps the most important discovery from the Marine Chemistry and Pharmacology Program has been that soft corals contain molecules that are potent inhibitors of inflammation and its associated pain. One important class of compounds, called pseudopterosins, are extracted from the Caribbean soft coral Pseudopterogorgia elisabethae. These compounds were discovered by collaborative chemical and pharmacological studies undertaken by Sea Grant graduate trainees from the Santa Barbara and San Diego campuses. The pseudopterosins have been developed through a licensing agreement with OsteoArthritis Sciences Inc. One new drug, methopterosin (fig. 1), a simple derivative of the natural pseudopterosins, has been developed from this discovery and has been approved by the U.S. Food and Drug Administration for clinical trials.

Methopterosin has a variety of important pharmacological properties that make it suitable for application to a number of conditions, including arthritis, psoriasis and inflammatory bowel disease, among others. Another unique feature of methopterosin is its ability to accelerate wound healing by over $400 \%$, a property of considerable interest in the treatment of burn victims, in postsurgical treatment and in drug therapies for the many disorders involved in the healing process. The combined anti-inflammatory and wound-healing properties of methopterosin assure that this class of marine-derived drugs will be developed for diverse applications.

An unexpected application of the pseudopterosins is as additives in skin care products. International skin care giant Estée Lauder is using "natural extracts" of $P$. elisabethae as additives in a product line called "Resilience." The natural extract produces pronounced reduction of skin inflammation from sunburn or irritation, and it also reduces degeneration of the skin. In the past 2 years, this one application of the pseudopterosins has generated average yearly royalty income of well over $\$ 750,000$ for UC.

Cancer has also been a major focus of Sea Grant research, and there have been significant achievements in this area as well. A unique cyclic compound, jasplakinolide (fig. 1), discovered by both the Santa Cruz and San 
Diego research groups, was found to be a powerful inhibitor of cancer cell growth. The compound, isolated from several sponges (for example, Jaspis spp. and Auletta constricta), proved of interest to the National Cancer Institute, where advanced testing against prostate carcinoma is now being planned. Jasplakinolide was found to affect cancer cells in a hitherto unknown way, by binding to specific proteins involved in cell division. Because of its unique properties, jasplakinolide has become commercially available as a research chemical through a company called Molecular Probes.

A second significant cancer-related discovery was recently announced by the San Diego research group. In fundamental studies of cellular processes, a sponge metabolite called ilimaquinone (fig. 1, from Hippospongia metachromia) was shown to inhibit cell division by binding to the Golgi apparatus, microscopic components of the cell that are essential to normal function. This significant discovery shows that ilimaquinone, or a suitable derivative, has the potential to provide an entirely new class of substances for the treatment of cancer.

\section{New directions for Sea Grant}

Like any developing science, marine drug discovery is changing in response to new technologies and new understandings. For example, advances in marine microbiology are now permitting study of microorganisms from the world's oceans. Once again Sea Grant researchers have taken the lead, this time in developing marine bacteria and fungi as a source for new drugs.

The potential of this new field was first demonstrated when the San Diego group studied bacteria taken from cores into the deep ocean floor. In those sediments, Scripps scientists discovered a previously unknown bacterium that produces a novel chemical substance that inhibits the growth of human colon tumor cells and also the human immunodeficiency virus (HIV), the causative agent in AIDS. This new bacterium, when cultured in a seawater-nutrient solution, produces a molecule of a type never seen before, macrolactin A (fig. 1). Over the past several years, this discovery has been extended to define the sources of marine microorganisms and their culture requirements. New technologies, including salt-resistant culture vessels, are also being developed.

This new area of study has also provided exciting discoveries in the inflammation program. Microorganisms have been discovered that produce potent new anti-inflammatory agents, some of which are currently under development. One such example is the estuarine bacterium, Streptomyces sp. (strain CNB-984), which produces cyclomarin A (fig. 1), a molecule composed of a cyclic array of amino acids. Importantly, four of the amino acids contained in this structure have never been seen before. Cyclomarin A has been found to be a powerful inhibitor of skin inflammation, and is active both when applied directly to the skin and when taken orally. This potentially important compound has been licensed to Phytera Inc., which is developing it for therapeutic application.

Although bacteria are the most common microorganisms in the oceans, more recent explorations by the research groups at UC Santa Cruz and UC San Diego have shown that fungi also have medical potential. Based on the revolutionary finding that penicillin could be derived from ordinary bread mold, marine fungi that occur inside marine invertebrates and on the surfaces of most marine plants and animals are now being considered for new drugs. In preliminary testing, the San Diego group has identified eight very different marine fungi that produce compounds that inhibit cancer cell growth. Although these compounds have not yet been identified, these findings indicate that the fungi will be an exciting source for new drugs.

Sea Grant's role in marine drug discovery has been crucial to the development of this field. For most of the past
20 years, it was Sea Grant, virtually alone, that invested in the development of this endeavor. Thanks to the program's efforts, marine organisms are emerging as among the most important frontiers for the development of badly needed new drugs. Based on the successes to date, we are optimistic that the world's oceans can meet the challenge to provide drugs for the next century.

W. Fenical is Director, Center for Marine Biotechnology and Biomedicine, Scripps Institution of Oceanography, UC San Diego.

\section{Further Reading:}

Faulkner DJ. 1995. Chemical riches from the oceans. Chem in Brit 31:680-4.

Fenical W. 1996. Marine biodiversity and the medicine cabinet: The status of new drugs from marine organisms. Oceanography 9(1):23-7.

Fenical W. 1993. Marine bacteria: Developing a new chemical resource. Chem Rev 93:1673-83.

Hay ME, Fenical W. 1996. Chemical ecology and marine biodiversity: Insights and products from the sea. Oceanography 9(1):10-20

Potts BCM, Faulkner DJ, Jacobs RS. 1992. Phospholipase A2 inhibitors from marine organisms. J Nat Prod 55:1701-17

Senderowicz AMJ, Kaur G, Sainz E, et al. 1995. Jasplakinolide: Inhibition of prostate carcinoma cell growth in vitro with disruption of the actin cytoskeleton. J Nat Cancer Inst $87: 46-51$. 